\title{
MONITORING LAND USE AND LAND COVER CHANGES USING GEOSPATIAL TECHNIQUES, A CASE STUDY OF FATEH JANG, ATTOCK, PAKISTAN
}

\author{
Aqil Tariq ${ }^{1 *}$, Hong Shu ${ }^{1}$, Saima Siddiqui ${ }^{2}$, Muhammad Imran ${ }^{3}$, Muhammad Farhan ${ }^{4}$ \\ 'State Key Laboratory of Information Engineering in Surveying, Mapping and Remote Sensing, Wuhan University, \\ 430079, Wuhan, Hubei, China \\ ${ }^{2}$ Department of Geography, University of the Punjab, Lahore, Punjab, Pakistan \\ ${ }^{3}$ Institute of Geoinformation and Earth Observation PMAS-Arid Agriculture University, Rawalpindi, 46300, Pakistan \\ ${ }^{4}$ School of Earth Sciences and Engineering, Hohai University, Nanjing (210098), China \\ *Corresponding author: aqiltariq@whu.edu.cn / aqiltariq85@gmail.com \\ Received: June 30 ${ }^{\text {th }}, 2020$ / Accepted: February 16 ${ }^{\text {th }}, 2021$ / Published: April 1 ${ }^{\text {st }}, 2021$ \\ https://DOI-10.24057/2071-9388-2020-117
}

\begin{abstract}
Change of land use and land cover (LULC) has been a key issue of natural resource conservation policies and environmental monitoring. In this study, we used multi-temporal remote sensing data and spatial analysis to assess the land cover changes in Fateh Jhang, Attock District, Pakistan. Landsat 7 (ETM+) for the years 2000, 2005 and 2010 and Landsat 8 (OLI/TIRS) for the year 2015 were classified using the maximum likelihood algorithms into built-up area, barren land, vegetation and water area. Post-classification methods of change detection were then used to assess the variation that took place over the study period. It was found that the area of vegetation has decreased by about $176.19 \mathrm{sq}$. $\mathrm{km}$ from 2000 to 2015 as it was converted to other land cover types. The built-up area has increased by 5.75\%. The Overall Accuracy and Kappa coefficient were estimated at 0.92 and $0.77,0.92$ and 0.78, 0.90 and 0.76, 0.92 and 0.74, for the years 2000, 2005, 2010 and 2015, respectively. It turned out that economic development, climate change and population growth are the main driving forces behind the change. Future research will examine the effects of changing land use types on Land Surface Temperature (LST) over a given time period.
\end{abstract}

KEY WORDS: Remote sensing; Geo-spatial techniques; Change detection; Land use; Land cover; Driving forces

CITATION: Aqil Tariq, Hong Shu, Saima Siddiqui, Muhammad Imran, Muhammad Farhan (2021). Monitoring Land Use And Land Cover Changes Using Geospatial Techniques, A Case Study Of Fateh Jang, Attock, Pakistan. Geography, Environment, Sustainability, Vol.14, No 1, p. 41-52 https://DOI-10.24057/2071-9388-2020-117

ACKNOWLEDGEMENTS: Aqil Tariq conducted the overall analysis and led the writing of the manuscript, design and data analysis. Hong Shu provided technical inputs, overall supervision for the research and reviewed the paper. Saima Siddiqui revised and corrected the manuscript. Muhammad Imran and Muhammad Farhan lend their support to the authors by writing the analysis of Landsat 7 (ETM+) and Landsat 8(OLI). This work is supported jointly by the National Key Research Development Program of China 576 (No. 5712017 YFB0503604 and No.2017YFB0503604), National Natural Science Foundation of 577 China (No.61971316) and State Key Laboratory of Satellite Navigation System and Equipment 578 Technology.

Conflict of interests: The authors reported no potential conflict of interest.

\section{INTRODUCTION}

Natural and human-induced changes in an urban environment are of concern nowadays due to their influence on the environment and human health (Han et al. 2015), which makes the research of LULC dynamics fundamental for proper natural resource planning and utilization as well as its management (Rawat and Kumar 2015). Conventional approaches for collecting population data, conducting surveys and evaluating environmental samples are not appropriate for complex multi-factorial ecological studies (Dong et al. 2009). For many of the challenges often encountered in environmental research that include processing of multidisciplinary data, more advanced techniques such as satellite Remote Sensing (RS) and Geographic Information Systems (GIS) are required.
Such tools provide necessary information for the analysis and environmental management of natural resources ( $\mathrm{L}$. Li et al. 2016).

One of the recent development trends is to perform geospatial studies using integrated analysis of satellite and geographical data. GIS is an optimized computer hardware and software system that can record, archive, retrieve, control, interpret and view geographically referenced (spatial) information to help development-oriented management and decision-making processes (Mahmood et al. 2014). GIS and RS have a wide range of applications in the fields of environment, agriculture and combined eco-environmental assessment (Behera et al. 2012; Qian 2016). Several researchers have focused on the negative impact of LULC changes on the ecological features of an area (Yulianto et al. 2019). Human-induced environmental 
changes are generating regional combinations of environmental factors that could slip beyond the envelope within which many of a region's terrestrial plants have grown within the next 50 to 100 years (X. Li et al. 2016).

Lu et. al (2004) explored several methods for the LULC change detection. A land use prediction model for a given period of time can be established by analysing chronological LULC changes. The model could give a framework for the real land use analysis, preparation, management and environmental protection in a region as well as recommendations for the local social and economic improvement (Galicia and García-Romero 2007; Lu et al. 2004; Masum and Islam 2020; Reis 2008). Up-todate knowledge on land cover changes calls for technical improvements in the methods for identifying LULC of any area (Mishra et al. 2016; Pervez et al. 2016). RS and GIS are essential and the most common techniques for obtaining detailed and timely spatial data on LULC and to analyse its regional changes (Lee et al. 2012; Pradhan et al. 2009; Singh S. and Rai 2018). Satellite imagery can be used to easily track land use changes, providing an outstanding foundation of statistics from which the information on LULC dynamics can be retrieved, tested and reproduced (Nachappa et al. 2019; Singh S.K. et al. 2018). Remote Sensing is thus commonly used at different scales for monitoring and managing the land use (Basim and Ali 2018; Hua 2017; Olokeogun et al. 2014). GIS offers a versatile framework for compilation, storage, display and review of digital data needed for identification of the landscape changes (Bansod and Dandekar 2018; Mishra et al. 2016; Tariq A. and Shu 2020; Vasenev et al. 2019; Vishwakarma et al. 2016).

The use of RS and GIS in numerous areas, including tracking and management of natural resources, land use transition, urban land use, environmental and demographic research, has been of great value to the property managers. Pixel-based information allows us to understand the interaction between different types of land cover and contributes to the design of improved methods for interacting with the landscape. Therefore, in the present research $\mathrm{RS}$ and geospatial methods were applied to assess the degree of urban land use change in Fateh Jhang district, particularly concerning the replacement of vegetation and natural land cover. The main purpose of this research was to use satellite imagery from the years 2000 to 2015 to identify and measure the LULC in the study area. The main objectives of this study were to identify the LULC changes in Fateh Jhang from 2000 to 2015, highlight the driving factors of LULC changes through combining remote sensing, environmental, geographical and socioeconomic data, and propose future sustainable land management practices to the policymakers to achieve land and sustainable development goals of the United Nations (UN).

\section{MATERIALS AND METHODS}

\section{Study Area}

Fateh Jhang is situated between $33^{\circ} 20^{\prime} \mathrm{N}$ to $33^{\circ} 55^{\prime} \mathrm{N}$ latitude and $72^{\circ} 23^{\prime} \mathrm{E}$ to $73^{\circ} 01^{\prime} \mathrm{E}$ longitude, covering an area of $1407.48 \mathrm{sq}$. km with elevation ranging from 336 to 939 meters asl (above sea level) and an estimated population of 340,414 people. The tehsil comprises 14 union councils (UCs) out of which only two UCs are urban (see Figure 1). It is located on the road between Islamabad and Kohat, 50 $\mathrm{km}$ from Islamabad and $48 \mathrm{~km}$ from Attock (Arshad et al. 2012). The soil in the study area was formed on calcareous loess deposits and is characterized as fine-textured, welldrained and moderately deep. Fateh Jhang consists of three distinct regions. In the northern part of the study area, north of the Kala-Chitta hills, there is a broad plateau, which is significantly broken down by ravines. The rich Sohan valley lies south of the Khairi-Murat town (near Dhari village) whereas a rugged plain lies between the two sides of the hills, narrow in the east and stretching westward (see Figure 1). Climate conditions vary from one region to another depending on the altitude. The soils of Fateh Jhang vary according to climate variation (Shaheen et al. 2015). In the city, the temperature is ranging from $45^{\circ} \mathrm{C}$ in summer to $15^{\circ} \mathrm{C}$ in winter. The daily mean maximum and minimum summer temperatures are $39^{\circ} \mathrm{C}$ and $27^{\circ} \mathrm{C}$ respectively (A. Tariq et al. 2020).

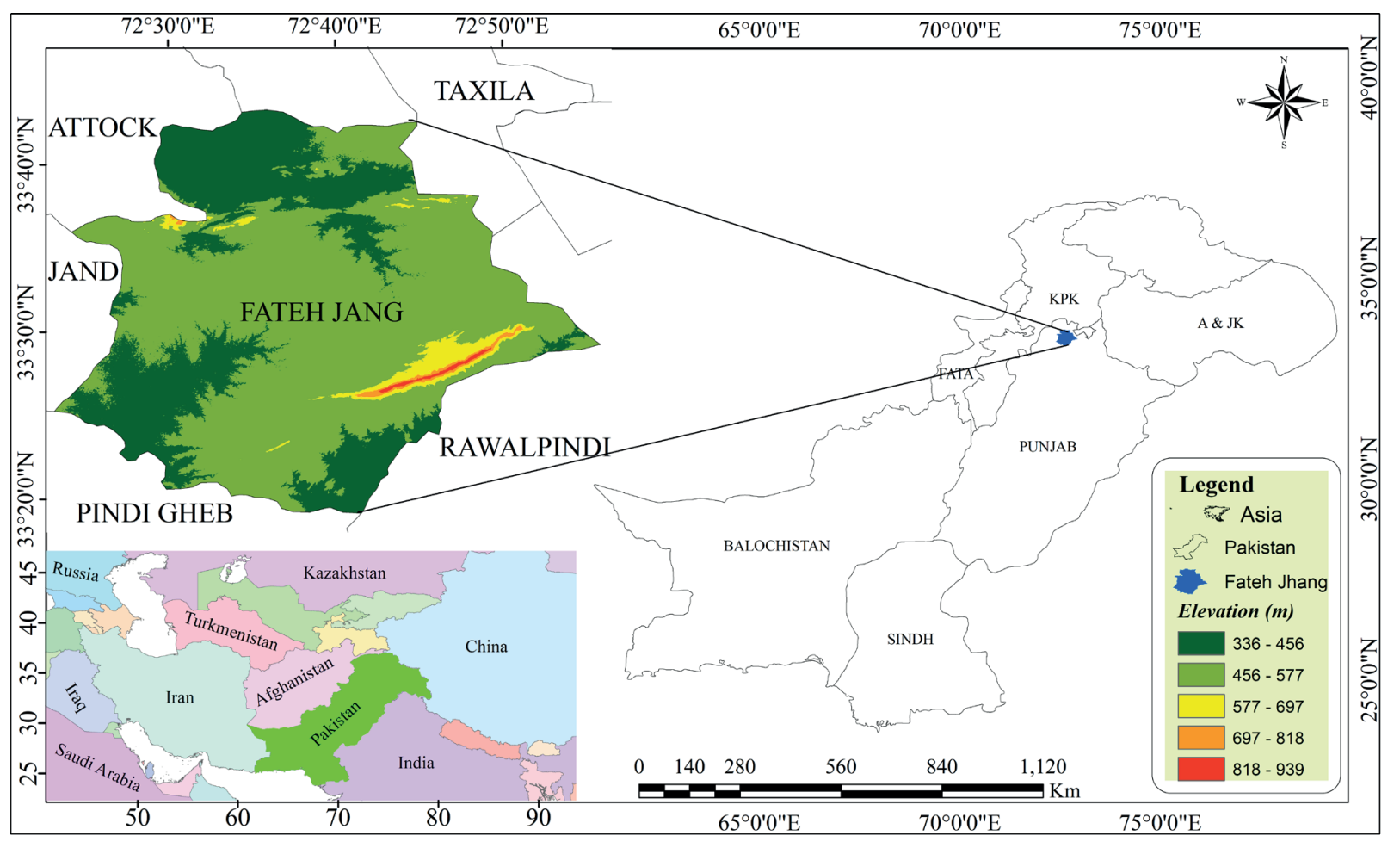

Fig. 1. Map of the Study area 


\section{Data acquisitions and processing}

For the present research, the Landsat 7 and 8 data for the years 2000, 2005, 2010 and 2015 were used. All the data were collected free of charge from the USGS-EROS (https://www.usgs.gov) and chosen so that the cloud cover is less than 10\% to improve the accuracy. Summary of the data used in the study is presented in Table 1. The shapefiles were created for the respective areas and the area of interest (AOI) was extracted using Erdas Imagine 2016 (Day, product level-1 G) and referenced using Universal Transverse Mercator (UTM) Projection System. The LULC maps of the study area were produced using ETM+ images with 8 bands (of which band 6 was a thermal band) and $30 \mathrm{~m}$ spatial resolution Landsat 7 images (bands 1-5 and 7). Using the method described by Jiménez-Muñoz et al. (2014), the thermal bands with $60 \mathrm{~m}$ spatial resolution were resampled to $30 \mathrm{~m}$. To obtain the LULC map from Landsat 8, 11-band images were used (bands 1-7 and 9 were OLI, 8 was panchromatic and 10 and 11 were thermal) (Table 2). Landsat 8 images had a spatial resolution of $30 \mathrm{~m}$, radiometric resolution of 12 bit and temporal resolution of 16 days. To match the data distribution, thermal bands with $100 \mathrm{~m}$ spatial resolution were also resampled to $30 \mathrm{~m}$ according to the method by Jiménez-Muñoz et al. (2014). Additionally, the authors committed to gathering field data over a five-month period. The collected data were used to classify several types of land cover within the study area. The primary purpose of the field survey was to collect land cover parcel data with the aid of GPS (global positioning system), which helped to demarcate the parcel boundaries using GIS software and historic maps. These GPS points were overlaid on the satellite image for boundary delineation and mapping. Field surveys were performed with the help of GPS, Maps.me and OSM-Tracker (both Open-StreetMap open-source mobile applications) for collecting the coordinates of different land cover types in the study area. High-resolution elevation data from Shuttle Radar Topography Mission (SRTM) were downloaded from the EarthData extraction tool "Application for Extraction and Exploration of Ready Samples (AppEEARS)" (https:// Ipdaac.usgs.gov/tools/appeears/) to produce the digital elevation model (DEM) of the study area. Vector data for tehsil and river systems as well as supplementary details were collected using RS and GIS Lab.

\section{Methodology}

The designed research procedure is presented in Figure 2 and includes using ArcMap 10.6, Erdas Imagine 2016 and Envi 5.4 tools to analyse different types of LULC and the interactions between them.

\section{Image pre-processing and LULC}

In Envi (5.4-version), the satellite data for 2000, 2005, 2010 and 2015 were optimized for noise reduction

Table 1. Data-collection used in the study

\begin{tabular}{|c|c|c|c|}
\hline Data & Acquisition date & Source & Processing level \\
\hline Landsat 7 (ETM) & 22 May 2000 & USGS Earth Explorer & TIER 1 \\
\hline Landsat 7 (ETM) & 12 May 2005 & USGS Earth Explorer & TIER 1 \\
\hline Landsat 7 (ETM) & 16 May 2010 & USGS Earth Explorer & TIER 1 \\
\hline Landsat 8 (OLI/TIRS) & 12 May 2015 & USGS Earth Explorer & TIER 1 \\
\hline SRTM & 11 Nov 2010 & Earth Data & \\
\hline Maximum Temperature & 1998-2016 & Pakistan Meteorological Department & Interpolated Maps \\
\hline Maximum Temperature & 1998-2016 & Pakistan Meteorological Department & Interpolated Maps \\
\hline Precipitation & $2000-2015$ & Pakistan Meteorological Department & Interpolated Maps \\
\hline
\end{tabular}

Table 2. Depiction of Landsat 7 and Landsat 8

\begin{tabular}{|c|c|c|c|c|c|c|c|}
\hline \multirow[t]{2}{*}{ S.No } & \multicolumn{3}{|c|}{ Landsat7 (ETM+) } & \multirow[t]{2}{*}{ Bands } & \multicolumn{3}{|c|}{ Landsat 8 (OLI \& TIRS) } \\
\hline & $\begin{array}{l}\text { Resolution } \\
\text { (Meter) }\end{array}$ & $\begin{array}{l}\text { Wavelength } \\
\text { (Micrometer) }\end{array}$ & Band Name & & Band Name & $\begin{array}{l}\text { Wavelength } \\
\text { (Micrometers) }\end{array}$ & $\begin{array}{c}\text { Resolution } \\
\text { (Meter) }\end{array}$ \\
\hline 1 & 30 & $0.45-0.52$ & Blue & & $\begin{array}{c}\text { Ultra-Blue } \\
\text { (coastal/aerosol) }\end{array}$ & $0.435-0.451$ & 30 \\
\hline 2 & 30 & $0.52-0.60$ & Green & & Blue & $0.452-0.512$ & 30 \\
\hline 3 & 30 & $0.63-0.69$ & Red & & Green & $0.533-0.590$ & 30 \\
\hline 4 & 30 & $0.77-0.90$ & NIR & & Red & $0.636-0.673$ & 30 \\
\hline 5 & 30 & $1.55-1.75$ & SWIR1 & & NIR & $0.851-0.879$ & 30 \\
\hline 6 & $60 *(30)$ & $10.40-12.50$ & Thermal & & SWIR1 & $1.566-1.651$ & 30 \\
\hline 7 & 30 & $2.09-2.35$ & SWIR2 & & SWIR2 & $2.107-2.294$ & 30 \\
\hline 8 & 15 & $0.52-0.90$ & Panchromatic & & Panchromatic & $0.503-0.676$ & 15 \\
\hline 9 & & & & & Cirrus & $1.363-1.384$ & 30 \\
\hline 10 & & & & & TIRS1 & 10.60-11.19 & $100 *(30)$ \\
\hline 11 & & & & & TIRS2 & $11.50-12.51$ & $100 *(30)$ \\
\hline
\end{tabular}




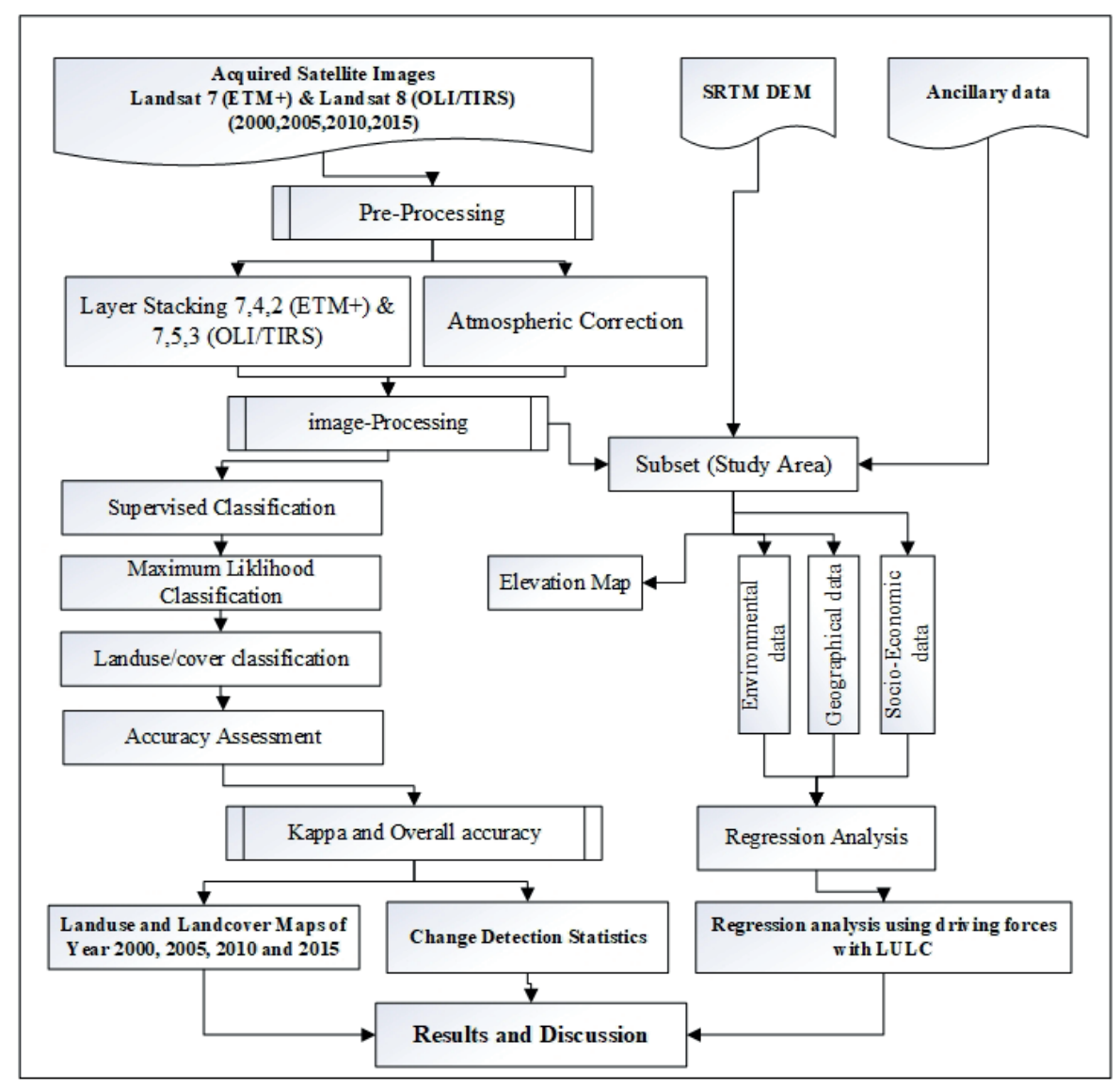

Fig. 2. Research methodology

purposes (Rasti et al. 2018). This was necessary for gathering certain relevant information on the data, such as the kind of sensors, utilized to collect the data, the angle of the sun at the time and date of data acquisition to identify the ambient conditions at the time of capture (Scheffler and Karrasch 2013). Before calibration of data for 2013, scanning lines were eliminated using Landsat_ gapfill (Envi extension/plugin) to improve the visual appearance of the images. According to the USGS-EROS (https://www.usgs.gov/faqs/what-landsat-7-etm-slcdata), a mechanical failure of the Scan Line Corrector (SLC) resulted in gaps known as scan lines in all Landsat 7 (ETM+) images which were collected after 31st May, 2003. Nonetheless, these items carried the identical geometric and radiometric properties as the data composed before the SLC failure and therefore can still be used. The ability of Envi and ArcMap to exchange and use information allowed to eradicate the scan lines. Envi 5.4 has the potential to calibrate multispectral bands in one go, saving time compared to previous models in which adjustment was performed on each band separately. The files for Envi must be prepared in TIFF format to interpret and group the bands in a directory. The resulting band format is an Envi file with the scanning lines removed using Landsatgapfil.Sav and with an extension .hdr and .emp. Thus, the data on each available band for the year 2015 was also removed from the scan line in 2015 and the resulting TIFF file for each band was transferred in Arc-Map 10.6.

The research has gone through strict site preparation which included using information collected from the field for the supervised data classification for the year 2015 to determine the land cover types for each of the Landsat classes. In addition to the classified data from 2015, the data from 2010, 2005 and 2000 were classified using Google Earth as a guide. The data was then trained in ArcMap after stacking the calibrated bands in combinations of 7, 4, 2 (2000, 2005 and 2010 data) and 7, 5, 3 (2015 data) (Chen et al. 2016; Mohammady et al. 2015). Such combinations were chosen instead of 4, 3, 2 because they were more useful for land use and land cover studies as it was very challenging to use the latter when classifying the data. Meanwhile, the used combinations allowed for a clear distinction between damaged fields and barren-land as well as different types of vegetation. So, the Landsat data were all classified using regulated classification for the four different years. The supervised selection included training sites, which were chosen based on the knowledge of the analyst in the researched subject. The qualifying locations were further utilized to produce the classification of image data using the classifier algorithm by matching the required pixels based on maximum likelihood. The above-mentioned method is frequently implemented as a classification algorithm and uses mathematical judgment rule which analyses the likelihood function of a pixel for every class and assigns pixel to the most probable class (Firdaus 2014).

Unlike the supervised classification, in the unattended classification, the program produces an automatic classification either by K-means or by ISO-Data so that the analyst cannot influence the created classes (Pandya et al. 2013). In both cases, the spectral grouping produced by the classification was based on the spectral variation and did not require the user to have extensive knowledge of the area of study. Types of land use that were identified included vegetation, built-up area, barren land and waterbodies. Unlike the 2015 data, the images for 2000, 2005 and 2010 were categorized using Google Earth and the colour representation of the 7,4,2 band combination as given by Google Earth (Chen et al. 2016; Mohammady et al. 2015). 


\section{Evaluation of Training samples and Accuracy assessment}

The training samples obtained from specific parts of the study area represented a total area of 1407.48 sq. km. An overview of the training samples that were used in the image classification is given in Table 3 \& Figure 3. First of all, a grid polygon was created in Arc Map 10.6 using a fishnet method, then a training sample from each grid cell was collected using a random sampling method.

In addition, evaluation of the classification accuracy was done using ArcMap 10.6 for the years 2000, 2005, 2010 and 2015. The adopted method of the postclassification accuracy assessment describes the quality of the resulting data (Firdaus 2014; Pandya et al. 2013; Rwanga and Ndambuki 2017). The following formula was used to calculate the overall accuracy (OA) and Kappa coefficient $(K c)$ values:

$$
K c=\frac{N \sum_{i=1}^{i} X i i-\sum_{i=1}^{r}\left(x_{i+} \times x_{+i}\right)}{N 2-\sum_{i=1}^{r}\left(x_{i+} \times x_{+i}\right)}
$$

Where

$r=$ the number of rows,

$x^{i}=$ the number of observations in row $\mathrm{i}$ and column $\mathrm{i}$,

$x_{i+}=$ the marginal totals of row

$x_{i+i}^{1+}=$ the marginal totals of column,

and $N$ is the overall number of detected pixels (Firdaus 2014; Pandya et al. 2013). X corresponds to the reference value (corrected and total) of the data and has a considerable influence on the accuracy of image classification. If its value is between 0.8 and 1 , then the classification can be considered accurate; when it is in the range of 0.40 to 0.80 , the classification is moderately accurate and the values from 0.00 to 0.40 mean that the classification was not accurate (Firdaus 2014; Pandya et al. 2013). Apart from 2000 and 2015 classified images that were evaluated using 65 ground validity samples from Google Earth's historical data, the 2015 image was also evaluated using 65 ground validation samples collected from the field surveys. In ArcMap, the actual calculation of accuracy was done by establishing reference points or ground control points, converting reference points from vector to raster data, integrating raster data with stable images and producing the uncertainty matrixes. The spatial resolution of the Landsat images was $30 * 30$ meter (Firdaus 2014; Kulkarni 2017; Pandya et al. 2013; Rwanga and Ndambuki 2017).

Table 4 provides details on the data quality assessment tests for the year 2015 and a summary of the error matrix. Applying the equation (1), the corresponding kappa coefficient $(\mathrm{kc})$ would therefore be the following:

$$
K c=\frac{(65 *(5+49+1+5)-E\{(6 * 5)+(52 * 51)+(1 * 1)+(7 * 7)\})}{\left(65^{2}-E\{(6 * 5)+(52 * 51)+(1 * 1)+(7 * 7)\}\right)}
$$

$\mathrm{Kc}=0.78$

This result is smaller than the overall accuracy $(O A)$ which is calculated by simply dividing the number of correctly classified cells over the total number of sampled cells.

The classification conducted for the year 2015 was mostly accurate and reliable as $0.929>0.80$ and closer to 1 . The values of $\mathrm{Kc}$ for the years 2000, 2005, 2010 and 2015 were estimated at $0.77,0.78,0.76$ and 0.78 respectively (Table 5 ). This also implies that, given the random collection of reference points, the classifications conducted on those images can be considered accurate and reliable.

\section{Driving factors of the LULC change}

According to the relevant studies, three groups of LULCC driving factors, namely socio-economic, environmental and geographical, are commonly defined. We selected five variables representing these factors. Since the paper focused mainly on analysing the relative impact of the driving forces time-series on the land use change, the neighbourhood factors in the study were considered as spatially contextual data. Geographical variables are the main determinants of the magnitude of land use changes. The possible range of LULCC is influenced by environmental factors, such as precipitation

Table 3. Summary of the training samples

\begin{tabular}{|c|c|c|c|c|}
\hline \multirow{2}{*}{ Classes } & \multicolumn{4}{|c|}{ Training Samples (in sq. km) } \\
\cline { 2 - 5 } & 2000 & 2005 & 2010 & 2015 \\
\hline Vegetation & 2.2 & 1.3 & 2.3 & 2.5 \\
\hline Built-up area & 3.2 & 1.9 & 2.8 & 2.2 \\
\hline Bare land & 0.4 & 2.1 & 2.6 & 2.4 \\
\hline Water & 1.5 & 3.2 & 2.4 & 2.6 \\
\hline
\end{tabular}

Table 4. 2015 error matrix table (in the number of pixels)

\begin{tabular}{|c|c|c|c|c|c|}
\hline Classified & Barren land & Vegetation & Built-up area & water & 0 \\
\hline Barren land & 5 & 0 & 0 & 0 & 5 \\
\hline Vegetation & 1 & 49 & 1 & 0 & 52 \\
\hline Built-up area & 0 & 0 & 0 & 5 & 7 \\
\hline Water & 0 & 2 & 1 & 7 & 7 \\
\hline Reference Total & 6 & 51 & 0 & \\
\hline
\end{tabular}

Table 5. Accuracy assessment of 2000, 2005, 2010 and 2015 classification

\begin{tabular}{|c|c|c|c|c|}
\hline Accuracy assessment & 2000 & 2005 & 2010 & 2015 \\
\hline OA (in percentage) & 0.92 & 0.92 & 0.90 & 0.92 \\
\hline Kappa (in percentage) & 0.77 & 0.78 & 0.76 & 0.78 \\
\hline
\end{tabular}




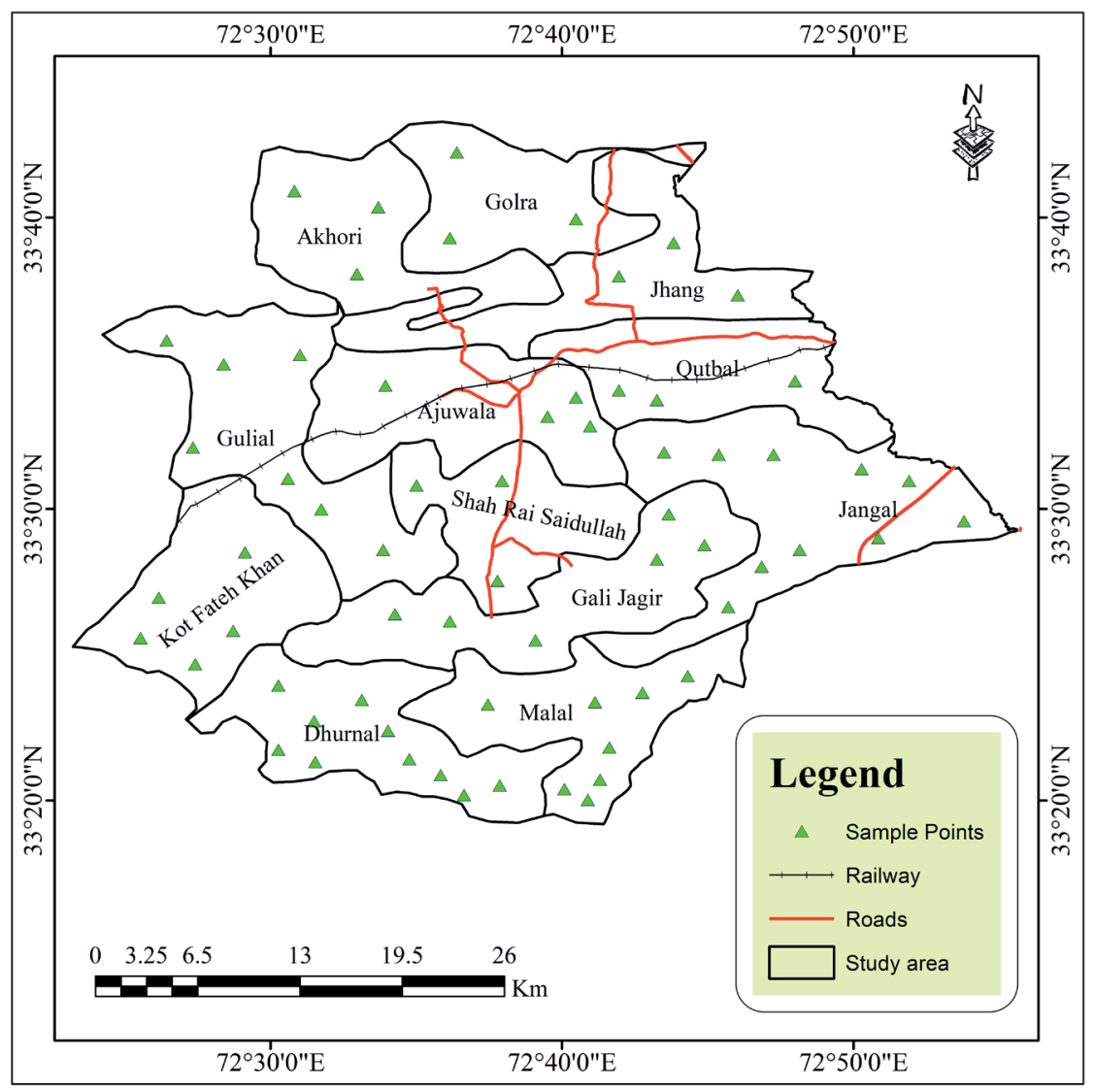

Fig. 3. Sample collection for Accuracy assessment

and temperature, which determine the water supply. Annual precipitation $(x 1)$, as well as the minimum ( $x 2$ ) and maximum temperature $(x 3)$ were therefore included as climate factors for the study of LULCC driving factors at Fateh Jhang. The data on the environmental factors were obtained from the Pakistan Meteorological Department, Islamabad https://www.pmd. gov.pk/. Socioeconomic data included time-series of regional gross domestic product (GDP) ( $x 4)$ and population ( $x 5$ ). These data were acquired from the Census Department of Pakistan Statistical Bureau, Islamabad (http://www.pbs.gov.pk/content/ population-census). Both those parameters were taken from Fateh Jhang 's statistical yearbook. These factors reflect the dynamics of population, urbanization, economic and industrial development, social investment and technological progress as well as conditions of the external traffic, which can potentially influence LULC changes in Fateh Jhang city. In this research, linear regression analysis was carried out to explore the underlying processes of the LULC adjustment in response to the chosen geographical, socio-economic and environmental factors. Thus, the time-series data on the four major land use types were used to explore the driving forces contributing to the land use change in Fateh Jhang. The four major land use types, that is, built-up area, vegetation, barren land and water were labelled as $y 1, y 2, y 3$ and $y 4$, respectively. A well-known multivariate statistical instrument for high-dimensional data processing is the Least Square Method (Carrascal et al. 2009; Vijayakumar et al. 2014). Multiple linear regression analysis, canonical correlation analysis, and key component analysis are included in the Least Square method function. After its application in several fields, including first chemometrics, sensory assessment, statistics, and ecology, it also emerged in social sciences and became popular (Kabir et al. 2017). The increasing popularity of the Least Square method compared to the traditional statistical analysis is partly due to its more efficient treatment of multicollinearity in the dataset, which is especially valuable in some cases when there are fewer measurements relative to the number of explanatory variables (Rosipal and Trejo 2000).

\section{RESULTS AND DISCUSSION}

Landsat 7 and 8 images were used for the years from 2000 to 2015 to study the spatial variation of land use, its dynamics and consequent adjustments. Supervised classification methods were used for all the images and the land use types were organized into four classes: vegetation, built-up area, barren land and water. The total area that was covered by the research amounted to $1407.48 \mathrm{sq}$. km. The changes observed in the land use of the study region over the sixteen years were summarized and presented in tabular format. Analysis of the classified images as shown in Figure 4 a revealed that in the year 2000 vegetation covered 800.74 sq. $\mathrm{km}$, which makes it the most prevalent type of land use/land cover in the study area. Barren land covered an area of 258.34 sq. km, while built-up and water classes amounted to $229.56 \mathrm{sq} . \mathrm{km}$ and $118.84 \mathrm{sq}$. km, so their share in the total area was far less significant.

The analysis of the Landsat 7 (ETM+) image for the year 2005 has shown that vegetation remained the leading class in the region with an area of $694.86 \mathrm{sq}$. km (Figure 4b). Territories that were classified as built-up areas covered 256.34 sq. km whereas the barren land and water types amounted to 337.44 and 118.84 sq. km, respectively (Khan 2015). Figure 4c shows that in 2010 vegetation and/or agricultural land also was the most common land cover type in Fateh Jhang with an area of $658.22 \mathrm{sq}$. km. The area of $288.66 \mathrm{sq}$. km corresponded to built-up territories, while barren land covered 341.76 sq. km. The remaining class was water bodies which covered a total area of 118.84 sq. km. In 2015 the total estimated built-up area was $310.55 \mathrm{sq}$. km. Vegetation/ agricultural land was still the most prominent land cover type in Fateh Jhang, covering an area of 624.55 sq. km. Barren land occupied an area of 353.54 sq. km, while water area amounted to 118.84 sq. km. From Figure 4a it can be seen that over the period between 2000 to 2005, vegetation area has changed significantly, particularly in the northern part of the study area, as it decreased by almost 105.88 sq. km, built-up area increased by 26.78 sq. km, barren 


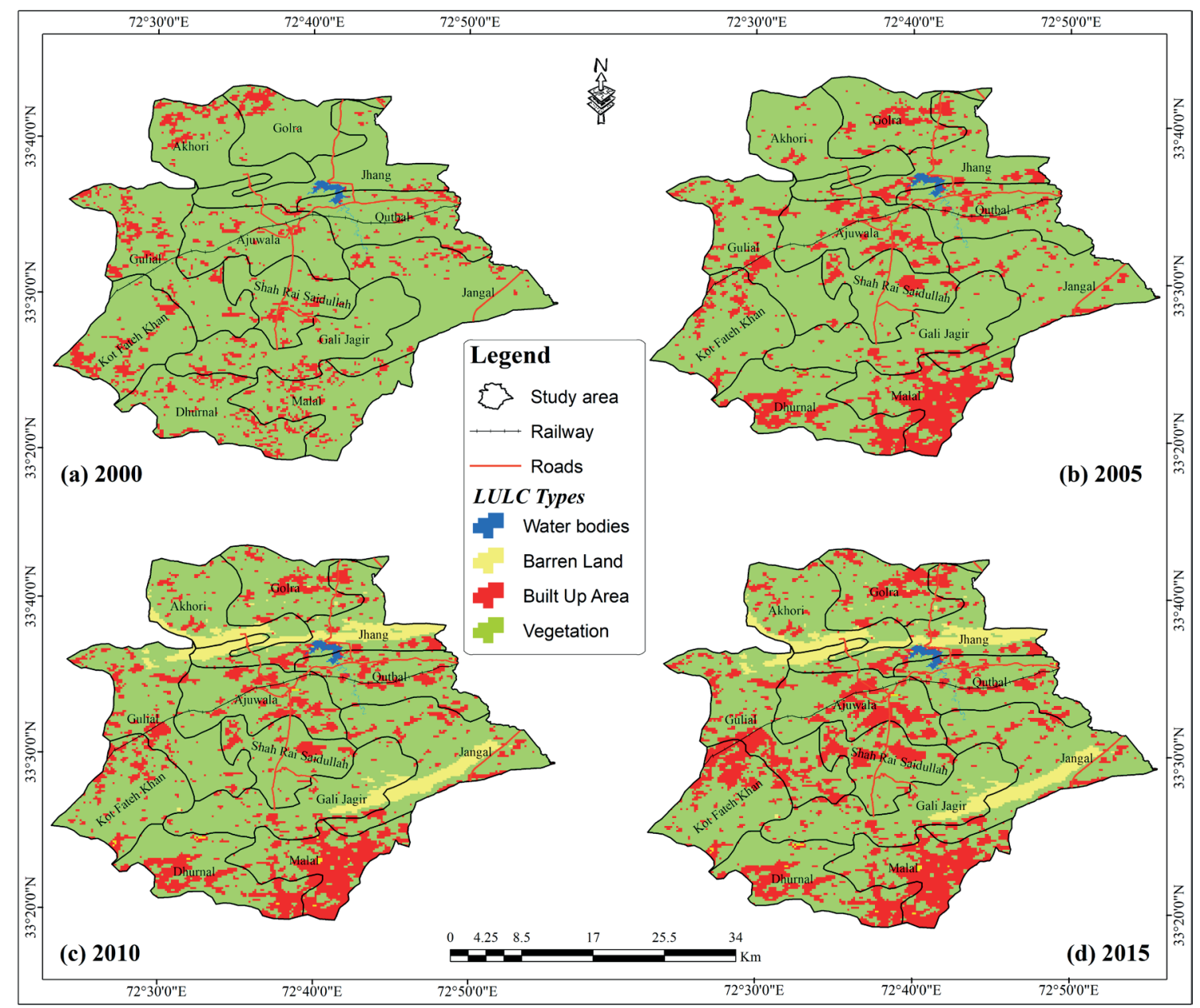

Fig. 4. Landuse Landcover maps a) 2000, b)2005, c)2010, and d)2015 of Fateh Jhang

land increased by $79.1 \mathrm{sq}$. km. Water bodies had some spatial changes during this period but their total area remained almost the same. From 2005 to 2010, there was a 32.32 sq. km increase in built-up area and $36.64 \mathrm{sq}$. $\mathrm{km}$ reduction of vegetation area (Figure 5). Barren land increased by $4.32 \mathrm{sq}$. km during this period. From 2010 to 2015, barren land increased by 11.78 sq. km and built-up area further increased by $21.89 \mathrm{sq} . \mathrm{km}$ in just five years. From 2000 to 2015, built-up area cover increased by 80.99 sq. $\mathrm{km}$, vegetation decreased by $176.19 \mathrm{sq} . \mathrm{km}$ and barren land experienced a $95.2 \mathrm{sq}$. km increase.

\section{Statistical description of LULC change}

The results of the classification were further analysed in terms of changes that happened among the observed groups. The first group covered the period from 2000 to 2005, the second group consisted of the period from 2005 to 2010, the third group consisted of the period from 2010 to 2015 and the fourth group corresponded to the period from 2000 to 2015.

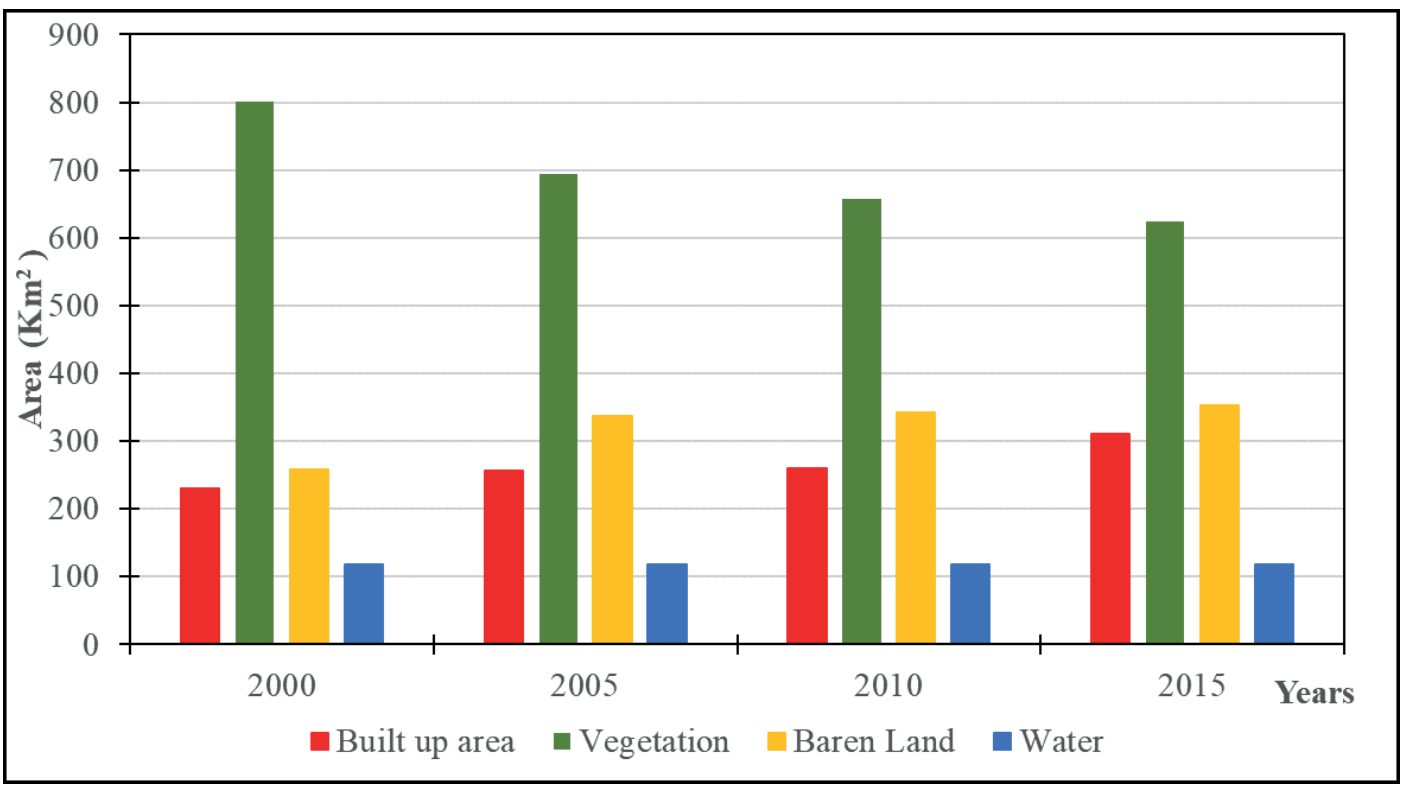

Fig. 5. The area of land use land cover types for different years 


\section{Statistical description of LULC change from 2000 to 2005}

The analysis of LULC changes over the study period revealed that the total area of barren-land increased by $5.62 \%$. It retained $52.81 \%$ of its initial area and $26.79 \%$ of it was transformed into vegetation (Table 6). The built-up area benefited $12.11 \%$ due to the transition from vegetation. Vegetation only maintained $46.24 \%$ of its initial area. Generally, from 2000 to 2005, its total area declined by 7.52\%, while $26.79 \%$ of it was converted from barren land zones, $16.45 \%$ from built-up and $22.56 \%$ from water. Two of the last groups in terms of land cover change were vegetation and water, the latter witnessed an unprecedented increase of $18.17 \%$ over the study period, whereas barren land and built-up area increased by 34.23 and $121.26 \%$, respectively.

This period reflects the most significant land cover transition in the study area. In five years, the area of vegetation shrank by $25.36 \%$, losing $18.55 \%$ to barren land and $12.11 \%$ to built-up area. The built-up region covered $12.11 \%$ of vegetation, $19.23 \%$ of barren-land and $23.25 \%$ of water areas. Total built-up area increased by $1.9 \%$ over the period from 2000 to 2005.

\section{Statistical description of LULC change from 2005 to 2010}

Within these five years, vegetation area decreased rapidly by $2.60 \%$, losing $11.66 \%$ to built-up area and $23.48 \%$ to barren land (Table 7 ). The built-up area covered $15.32 \%$ of vegetation area, $23.56 \%$ of barren-land and $19.21 \%$ of water areas. Vegetation cover was removed from $39.26 \%$ area. The barren land area mostly emerged from vegetation (23.48\%) and built-up area (16.01\%) and benefited more from agricultural land (21.35\%) than any land cover type over the time period.

\section{Statistical change detection of LULC from 2010 to 2015}

This time span (2010-2015) had showed the utmost recent change in land cover at time of study. Within five years, vegetation area had fallen rapidly by $2.60 \%$, losing $11.66 \%$ to the built-up area and $23.48 \%$ to the barren-land (Table 8 ). The built-up area had covered $15.32 \%$ of the trees area, $23.56 \%$ of the barren-land and $19.21 \%$ of the water areas. Vegetation cover was removed from $39.26 \%$ area. Barren-land areas had grown mostly from vegetation $23.48 \%$ and built-up area $16.01 \%$ and benefited more from agricultural land $21.35 \%$ than any land cover over the time period.

Table 6. Statistical description of LULC change between 2000 and 2005

\begin{tabular}{|c|c|c|c|c|c|}
\hline \multicolumn{6}{|c|}{2000 INITIAL STATE\% } \\
\hline 2005 FINAL STATE \% & & Built-up & Vegetation & Barren land & Water \\
\hline & Built-up & 50.95 & 12.11 & 19.23 & 23.25 \\
\hline & Vegetation & 16.45 & 46.24 & 26.79 & 22.56 \\
\hline & Barren land & 16.3 & 18.55 & 52.81 & 4.19 \\
\hline & Water & 16.3 & 23.10 & 1.17 & 50.00 \\
\hline & Total & 100 & 100.00 & 100.00 & 100 \\
\hline & Class Change & 1.90 & -7.52 & 5.62 & 0 \\
\hline & Image Difference & 121.26 & -25.36 & 34.23 & 18.17 \\
\hline
\end{tabular}

Table 7. Statistical description of LULC change between 2005 and 2010

\begin{tabular}{|c|c|c|c|c|c|}
\hline \multicolumn{6}{|c|}{2005 INITIAL STATE\% } \\
\hline 2010 FINAL STATE \% & & Built-up & Vegetation & Barren land & Water \\
\hline & Built-up & 51.15 & 15.32 & 16.01 & 19.21 \\
\hline & Vegetation & 11.66 & 48.7 & 23.48 & 15.49 \\
\hline & Barren land & 23.56 & 26.80 & 50.16 & 15.3 \\
\hline & Water & 13.63 & 9.18 & 10.35 & 50 \\
\hline & Total & 100 & 100 & 100 & 100 \\
\hline & Class Change & 2.30 & -2.60 & 0.31 & 0 \\
\hline & Image Difference & 53.29 & -39.26 & 39.23 & 23.1 \\
\hline
\end{tabular}

Table 8. Statistical description of LULC change between 2005 and 2010

\begin{tabular}{|c|c|c|c|c|c|}
\hline \multicolumn{6}{|c|}{2010 INITIAL STATE\% } \\
\hline 2015 FINAL STATE \% & & Built-up & Vegetation & Barren land & Water \\
\hline & Built-up & 50.79 & 20.50 & 12.33 & 18.1 \\
\hline & Vegetation & 31.04 & 48.81 & 21.33 & 17.39 \\
\hline & Barren land & 10.43 & 24.50 & 50.42 & 14.51 \\
\hline & Water & 7.76 & 6.20 & 15.92 & 50 \\
\hline & Total & 100 & 100 & 100 & 100 \\
\hline & Class Change & 1.56 & -2.39 & 0.84 & 0 \\
\hline & Image Difference & 62.35 & 42.23 & 45.23 & 25.01 \\
\hline
\end{tabular}




\section{Statistical description of LULC change from 2000 to 2015}

The changes that occurred over the sixteen years summarize the trend in the land use change over the study period. Identification of the land use change as presented in Table 9 showed the area of barren land has increased by $6.76 \%$ over the period, built-up area witnessed a remarkable percentage increase of $5.75 \%$ indicating a steady growth in agricultural activities and improvement in the built-up parts of the study area. Such practices emerged from the fear that farms would extend outside their defined boundaries. Although it only increased by $1.90 \%$ by 2005 , it also gained $2.30 \%$ and $1.56 \%$ in 2010 and 2015 respectively.

\section{Relationship between Different Land Use Types and the Driving Factors}

Changes to the Fateh Jhang LULC were driven by a variety of environmental, geographical and socioeconomic factors. While population increase was one of the basic reasons for the urban sprawl, the role of secondary factors e.g., economic development had to be examined as well. To identify the impact of each independent variable on builtup area, vegetation, barren land and water, five variables (i.e., annual precipitation $(x 1)$, minimum temperature $(x 2)$, maximum temperature $(x 3)$, gross domestic product (GDP) $(x 4)$, and population $(x 5)$ were analysed to create a model. Table 10 illustrates the results in terms of VIP (Variable Importance in Progression) values and the contribution of environmental, geographical and socio-economic factors to the LULC change.

The impact of all these components on the land use change trend in the study area was confirmed by evaluating regression between the land use characteristics and variables, describing the environmental, population and economic influences. The determination coefficient of $0.88,0.98,0.86$, and 0.99 was calculated for the built-up area, vegetation, barren land and water bodies respectively, which indicates that $88 \%, 98 \%, 86 \%$ and $99 \%$ of the variation in land use types during the study period might be described by the selected underlying factors. The census data showed a significant increase in population during the study period. Urbanization and the establishment of new housing settlements caused a fast urban sprawl, which was mostly caused by the migration of rural population to cities. The growing population increased the pressure on the limited resource base which supposedly added to the urban land enlargement by de-forestation and filling of the low-lying fields.

Table 9. Statistical description of LULC change between 2000 and 2015

\begin{tabular}{|c|c|c|c|c|c|}
\hline \multicolumn{6}{|c|}{2000 INITIAL STATE\% } \\
\hline 2015 FINAL STATE \% & & Built-up & Vegetation & Barren land & Water \\
\hline & Built-up & 52.90 & 33.91 & 10.23 & 19.3 \\
\hline & Vegetation & 17.65 & 43.74 & 35.23 & 14.99 \\
\hline & Barren land & 14.75 & 16.23 & 53.38 & 15.71 \\
\hline & Water & 14.75 & 6.12 & 1.16 & 50 \\
\hline & Total & 100 & 100 & 100 & 100 \\
\hline & Class Change & 5.75 & -12.52 & 6.76 & 0 \\
\hline & Image Difference & 43.22 & -47.25 & 25.23 & 22.1 \\
\hline
\end{tabular}

Table 10. Analysis of the relationship between LULCC and its key driving factors

\begin{tabular}{|c|c|c|c|c|c|c|c|c|}
\hline LULC Type (y) & Precipitation (x1) & Min Temp (x2) & Max temp (x3) & GDP (x4) & Population (x5) & $R^{2}$ & Adjusted R & SE of Estimate \\
\hline Built up area (y1) & -0.027 & 0.068 & 0.104 & 0.101 & 0.93 & 0.88 & 0.76 & 3.45 \\
\hline Vegetation (y2) & -0.030 & -0.106 & -0.117 & -0.108 & -0.087 & 0.98 & 0.86 & 4.36 \\
\hline Barren land (y3) & -0.402 & -0.103 & -0.112 & -0.110 & 0.067 & 0.86 & 0.99 & 2.81 \\
\hline Water (y4) & -0.040 & 0.27 & 0.161 & 0.127 & 0.050 & 0.99 & 0.99 & 7.35 \\
\hline
\end{tabular}

Predictors: (constant), Population, GDP, Max Temperature, Min Temperature, Rainfall)

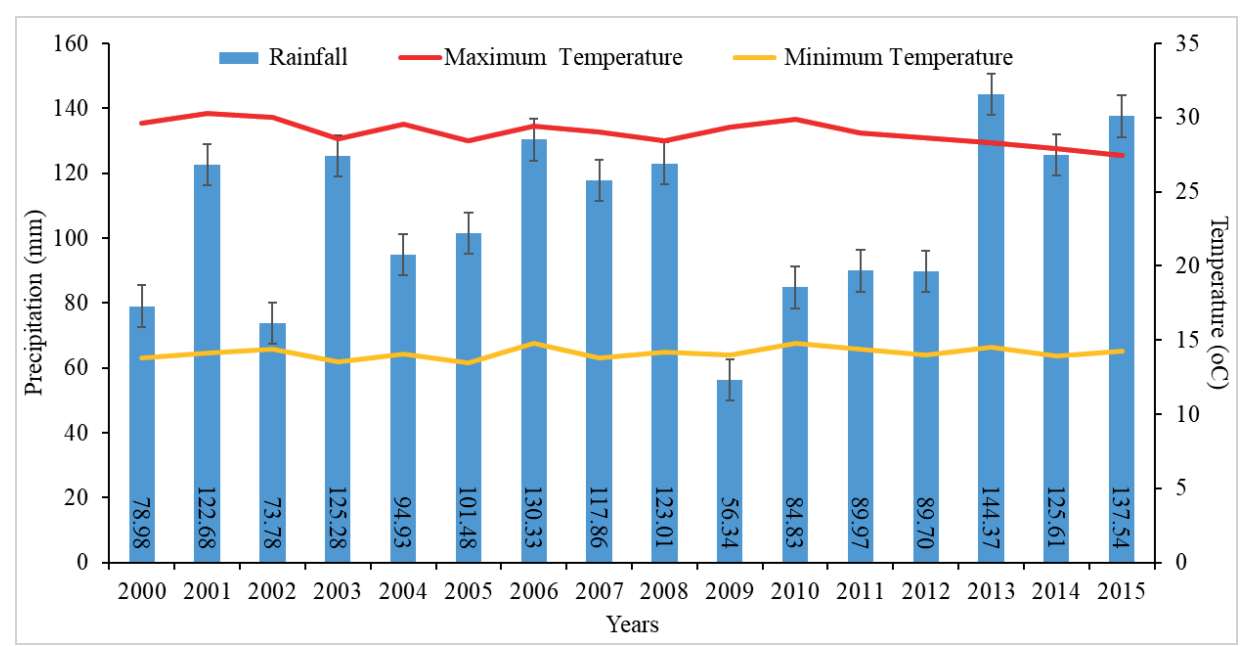

Fig. 6. Variation in Temperature $\left({ }^{\circ} \mathrm{C}\right)$ and Precipitation $(\mathrm{mm})$ in Fateh Jhang from 2000 to 2015 
There may be both positive and negative consequences of urban development on the environment but an uncontrolled urban sprawl will surely lead to undesirable effects. Both developing and developed countries have comparable environmental challenges related to urban sprawl. Built-up communities keep growing constantly along with residential and commercial production and parking areas and other infrastructures, that does not allow water to infiltrate the soil. As a result, the environment changes dramatically since the transition from the original state to an urban area is a non-reversible process. As urban land expands, a variety of vulnerable resources might become endangered. The period of urbanization that occurred in the periphery has contributed to the development of new relationships between different land use types, especially where historical and current patterns in land use are established side by side. Lack of agricultural land and uncontrolled growth of built-up areas are serious challenges of the current land use which have appeared due to the development of the new urban areas, which has led to difficulties in the transformation from various modes of life in the countryside and cities. Another contributing factor for rapid urbanization is the economic development of Fateh Jhang, particularly related to the construction of Islamabad airport, which is the most recent significant project in the area (https://fp.brecorder. com/2005/11/20051115352782/). Another major factor of increasing urbanization is industrialization. During the study period, it also resulted in the invasion of enormous numbers of pastoral immigrants.

One of the fundamental ways in which global climate change is projected to affect the economic activities in the area is through the impact of temperature and precipitation on agricultural production. The important ecological elements such as forest nitrogen cycle and agricultural productivity seem to be affected by climate change (Figure 6) (Raza et al. 2019; Rustad et al. 2012). Changes in precipitation, for example, may cause changes in hydrological fluxes, which in turn could result in changes in development, decomposition and absorption of nutrients. Correspondingly, temperature increase could also lead to changes in hydrological fluxes, soil disintegration and faster behavioural expansion, causing reduced yields and accelerated maturation (Bonan 2008; Hanson and Weltzin 2000). Precipitation is the most important factor in the continuing degradation of forests and agricultural land (Mousa et al. 2020). Higher rainfall has required a higher degree of output in some places of Pakistan and offered more water for irrigation. Due to the damage of fertile soils with extreme floods caused by regular rainfall or drought, the reverse effects were reported in some areas. The decreasing rate of woody biomass, on the other hand, is the second maximum in the world. It ranges from 4 to $6 \%$ annually (UNEP 2005). The climatic conditions that have escalated as a result of man-made and natural processes over the years are related to the reduction of forest area. The effect of temperature and precipitation on the vegetation area is confirmed by the regression analysis as the maximum temperature has increased and precipitation reduced over the years (Figure 6). As for driving factors, we have discussed three major groups of factors, including geographical, environmental and socioeconomic factors. All these variables (land enlargement, deforestation, immigration, economical changes, population growth, urbanization etc.) were characterized by population growth, GDP, precipitation and temperature. Intergovernmental Panel on Climate Change (IPCC) states that the shifts in ambient humidity and rainfall are led by an increase in the global average temperature. The effects of temperature rise include extreme flooding, storms, dried up rivers that were seasonal reservoirs until recently and erratic conditions such as irregular span of the rainfall season, which could be delayed, shortened or interrupted by recurrent drought incidents. All these processes are also visible when analysing the climate conditions in Fateh Jhang. We are trying to overcome all the above-mentioned factors by aiming at reaching a balance between urbanization, conserving water bodies, woodlands and vegetation area by implementing new management techniques. This research has described the structure of the study area, which improves our understanding of the land use and land cover changes during the past years and allows for site-specific recommendations to facilitate and enable more efficient land use planning and design for both agricultural and built-up areas.

\section{CONCLUSIONS}

In this research, digital image processing techniques were used to evaluate the LULC and identify its changes. The analysis showed that during the period from 2000 to 2015, urban areas increased, consequently causing a significant reduction of vegetation and barren land area. The increase in water area was insignificant. The main objectives of this study were to identify the LULC changes in Fateh Jhang from 2000 to 2015 and highlight the driving factors of LULC changes through combining remote sensing, environmental, geographical and socioeconomic data. It was estimated that between 2000 and 2015 the built-up area increased from $16.31 \%$ to $22.06 \%$ of the total area, while vegetation decreased from $56.89 \%$ to $44.37 \%$ and barren land increased from $18.35 \%$ to $25.12 \%$ respectively. The change of vegetation and barren land into urban territories has caused varied and extensive environmental degradation of the study area, the main negative outcome of which was related to the slum growth that accompanies quick urban development. Socio-economic development and population growth are the main driving factors of urban land expansion. The findings of this research indicate rapid growth of built-up land and decline in agricultural land and vegetation area during 2000-2015. The study revealed a strong influence of integrated driving factors on land use and land cover at the regional and national scale. The region of Fateh Jhang in Pakistan has undergone rapid, wide-ranging changes in the LULC intensified by the conversion of natural resources for food purpose, urbanization and other socio-economic benefits. This research would be helpful to the urban planning and design department for land sustainability development. 


\section{REFERENCES}

Arshad W., Ali S. \& Hussain M. (2012). Bars-09: a High Yielding and Rust Resistant Wheat (Triticum Aestivum L.) Variety for Rainfed Areas of Punjab. In J Agric. Res, 50, 189-201.

Bansod R.D. \& Dandekar U.M. (2018). Evaluation of Morna river catchment with RS and GIS techniques. Journal of Pharmacognosy and Phytochemistry, 7(1), 1945-1948.

Basim Y.M. \& Ali S.A. (2018). APPLICATION OF REMOTE SENSING AND GIS IN CHANGE DETECTION IN GREEN MOUNTIAN FOREST, LIBYA. In The fifth Scientific Conference of Environment and Sustainable Development In the Arid and Semi - Arid Regions (ICESD), 1-13.

Behera M.D., Borate S.N., Panda S.N., Behera P.R. \& Roy P.S. (2012). Modelling and analyzing the watershed dynamics using Cellular Automata (CA)-Markov model - A geo-information based approach. Journal of Earth System Science, 121(4), 1011-1024, DOI: 10.1007/ s12040-012-0207-5.

Bonan G.B. (2008). Forests and Climate Change: Forcings, Feedbacks, and the Climate Benefits of Forests. Science, 320(5882), 1444-1449, DOI: 10.1126/science.1155121.

Carrascal L.M., Galván I., \& Gordo O. (2009). Partial least squares regression as an alternative to current regression methods used in ecology. Oikos, 118(5), 681-690, DOl: 10.1111/j.1600-0706.2008.16881.x.

Chen Y., Wang Q., Wang Y., Duan S.B., Xu M. \& Li Z.L. (2016). A spectral signature shape-based algorithm for landsat image classification. ISPRS International Journal of Geo-Information, 5(9), DOI: 10.3390/ijgi5090154.

Dong L., Wang W., Ma M., Kong J. \& Veroustraete F. (2009). The change of land cover and land use and its impact factors in upriver key regions of the Yellow River. International Journal of Remote Sensing, 30(5), 1251-1265, DOI: 10.1080/01431160802468248.

Firdaus R. (2014). Doctoral Dissertation Assessing Land Use and Land Cover Change toward Sustainability in Humid Tropical Watersheds , Indonesia Assessing Land Use and Land Cover Change toward Sustainability in Humid Tropical Watersheds, Indonesia, (March), 0-1.

Galicia L. \& García-Romero A. (2007). Land Use and Land Cover Change in Highland Temperate Forests in the Izta-Popo National Park, Central Mexico. Mountain Research and Development, 27(1), 48-57, DOl: 10.1659/0276-4741(2007)27[48:Iualcc]2.0.co;2.

Han H., Yang C., \& Song J. (2015). Scenario simulation and the prediction of land use and land cover change in Beijing, China. Sustainability (Switzerland), 7(4), 4260-4279, DOI: 10.3390/su7044260.

Hanson P., \& Weltzin J. (2000). Hanson 2000 Drought and US Forests.pdf. The Science of the Total Environment.

Hua A.K. (2017). Land Use Land Cover Changes in Detection of Water Quality: A Study Based on Remote Sensing and Multivariate Statistics. Journal of environmental and public health, 2017, 7515130, DOI: 10.1155/2017/7515130.

Jiménez-Muñoz J.C., Sobrino J.A., Skoković D., Mattar C. \& Cristóbal J. (2014). Land Surface Temperature Retrieval Methods From Landsat-8 Thermal Infrared Sensor Data. IEEE Geoscience and Remote Sensing Letters, 11(10), 1840-1843, DOI: 10.1109/LGRS.2014.2312032.

Kabir A., Rahman J., Shamim A.A., Klemm R.D.W., Labrique A.B., Rashid M. et al. (2017). Identifying maternal and infant factors associated with newborn size in rural Bangladesh by partial least squares (PLS) regression analysis. PLoS ONE, 12(12), 1-16, DOI: 10.1371/journal. pone.0189677.

Khan S.A. (2015). Geochemical impact assessment of produced water of Sadqal oil and gas field on the soil surrounding the storage ponds in Fateh Jang area, Punjab, Pakistan. Journal of Himalayan Earth Sciences Volume, 48(2), 75-84, DOI: 10.1145/3132847.3132886.

Kulkarni N.M. (2017). Crop Identification Using Unsuperviesd ISODATA and K-Means from Multispectral Remote Sensing Imagery. International Journal of Engineering Research and Applications, 07(04), 45-49, DOI: 10.9790/9622-0704014549.

Lee S., Song K.-Y., Oh H.-J. \& Choi J. (2012). Detection of landslides using web-based aerial photographs and landslide susceptibility mapping using geospatial analysis. International Journal of Remote Sensing, 33(16), 4937-4966, DOI: 10.1080/01431161.2011.649862.

Li L., Lu D. \& Kuang W. (2016). Examining urban impervious surface distribution and its dynamic change in Hangzhou metropolis. Remote Sensing, 8(3), 19-24, DOI: 10.3390/rs8030265.

Li X., Wang Y., Li J., \& Lei B. (2016). Physical and socioeconomic driving forces of land-use and land-cover changes: A Case Study of Wuhan City, China. Discrete Dynamics in Nature and Society, 2016(2014), DOI: 10.1155/2016/8061069.

Lu D., Mausel P., Brondízio E., \& Moran E. (2004). Change detection techniques. International Journal of Remote Sensing, 25(12), 23652401, DOI: 10.1080/0143116031000139863.

Mahmood R., Pielke R.A., Hubbard, K. G., Niyogi, D., Dirmeyer, P. A., Mcal pine, C. et al. (2014). Land cover changes and their biogeophysical effects on climate. International Journal of Climatology, 34(4), 929-953, DOl: 10.1002/joc.3736.

Masum S.A. \& Islam M.S. (2020). A case study on predicting the environmental impacts of untreated effluent generated from Tannery industrial estate in Dhaka, Bangladesh. Geography, Environment, Sustainability, 13(3), 22-31, DOI: 10.24057/2071-9388-2019-127.

Mishra V.N., Rai P.K., Kumar P. \& Prasad R. (2016). Evaluation of land use/land cover classification accuracy using multi-resolution remote sensing images. Forum geografic, XV(1), 45-53, DOl: 10.5775/fg.2016.137.i.

Mohammady M., Moradi H.R., Zeinivand H. \& Temme A.J.A.M. (2015). A comparison of supervised, unsupervised and synthetic land use classification methods in the north of Iran. International Journal of Environmental Science and Technology, 12(5), 1515-1526, DOI: 10.1007/ s13762-014-0728-3.

Mousa B.G., Shu H., Freeshah M. \& Tariq A. (2020). A novel scheme for merging active and passive satellite soil moisture retrievals based on maximizing the signal to noise ratio. Remote Sensing, 12(22), 1-23, DOI: 10.3390/rs12223804.

Nachappa T.G., Piralilou S.T., Ghorbanzadeh O., Shahabi H. \& Blaschke T. (2019). Landslide susceptibility mapping for Austria using geons and optimization with the Dempster-Shafer theory. Applied Sciences (Switzerland), 9(24), DOI: 10.3390/app9245393.

Olokeogun O.S., Iyiola O.F. \& Iyiola K. (2014). Application of remote sensing and GIS in land use/land cover mapping and change detection in Shasha Forest Reserve, Nigeria. In International Archives of the Photogrammetry, Remote Sensing and Spatial Information Sciences - ISPRS Archives, 40, 613-616, DOI: 10.5194/isprsarchives-XL-8-613-2014.

Pandya M., Baxi A., Potdar M.B., Kalubarme M.H. \& Agarwal B. (2013). Comparison of Various Classification Techniques for Satellite Data. International Journal Of Scientific \& Engineering Research, 4.

Pervez W., Uddin V., Khan S.A. \& Khan J.A. (2016). Satellite-based land use mapping: comparative analysis of Landsat-8, Advanced Land Imager, and big data Hyperion imagery. Journal of Applied Remote Sensing, 10(2), 026004, DOI: 10.1117/1.jrs.10.026004.

Pradhan B., Lee S. \& Buchroithner M.F. (2009). Use of geospatial data and fuzzy algebraic operators to landslide-hazard mapping. Applied Geomatics, 1(1-2), 3-15, DOl: 10.1007/s12518-009-0001-5. 
Qian C. (2016). Impact of land use/land cover change on changes in surface solar radiation in eastern China since the reform and opening up. Theoretical and Applied Climatology, 123(1-2), 131-139, DOI: 10.1007/s00704-014-1334-5.

Rasti B., Scheunders P., Ghamisi P., Licciardi G. \& Chanusso, J. (2018). Noise reduction in hyperspectral imagery: Overview and application. Remote Sensing, 10(3), 1-28, DOI: 10.3390/rs10030482.

Rawat J.S. \& Kumar M. (2015). Monitoring land use/cover change using remote sensing and GIS techniques: A case study of Hawalbagh block, district Almora, Uttarakhand, India. Egyptian Journal of Remote Sensing and Space Science, 18(1), 77-84, DOI: 10.1016/j.ejrs.2015.02.002.

Raza A., Razzaq A., Mehmood S.S., Zou X., Zhang X., Lv Y. \& Xu J. (2019). Impact of climate change on crops adaptation and strategies to tackle its outcome: A review. Plants, 8(2) , DOI: 10.3390/plants8020034.

Reis S. (2008). Analyzing land use/land cover changes using remote sensing and GIS in Rize, North-East Turkey. Sensors, 8(10), 61886202, DOI: 10.3390/s8106188.

Rosipal R. \& Trejo L.J. (2000). CrossRef Listing of Deleted DOls, 1, 97-123, DOI: 10.1162/15324430260185556.

Rustad L., Campbell J., Dukes J.S., Huntington T., Lambert K.F., Mohan J. \& Rodenhouse N. (2012). Changing Climate, Changing Forests : The Impacts of Climate Change on Forests of the Northeastern United States and Eastern Canada. U.S.Forest Service, (August), 56.

Rwanga S.S. \& Ndambuki J.M. (2017). Accuracy Assessment of Land Use/Land Cover Classification Using Remote Sensing and GIS. International Journal of Geosciences, 08(04), 611-622, DOI: 10.4236/ijg.2017.84033.

Scheffler D. \& Karrasch P. (2013). Preprocessing of hyperspectral images: a comparative study of destriping algorithms for EO1-hyperion. Image and Signal Processing for Remote Sensing XIX, 8892, 88920H, DOI: 10.1117/12.2028733.

Shaheen A., Naeem M.A., Jilani G., Shaheen A., Naeem M.A., Jilani G., \& Shafiq M. (2015). Restoring the Land Productivity of Eroded Land through Soil Water Conservation and Improved Fertilizer Application on Pothwar plateau in Punjab Province, Pakistan Restoring the Land Productivity of Eroded Land through Soil Water Conservation and Improved. Plant Production Science ISSN:, 1008(196), 201. https://doi. org/10.1626/pps.14.196

Singh, S. K., Laari, P. B., Mustak, S., Srivastava, P. K., \& Szabó, S. (2018). Modelling of land use land cover change using earth observation data-sets of Tons River Basin, Madhya Pradesh, India. Geocarto International, 33(11), 1202-1222, DOI: 10.1080/10106049.2017.1343390.

Singh S. \& Rai P.K. (2018). Application of earth observation data for estimation of changes in land trajectories in Varanasi District, India. Journal of Landscape Ecology(Czech Republic), 11(1), 5-18, DOI: 10.1515/jlecol-2017-0017.

Tariq A., Shu H. (2020). Monitoring forest fire using Geo-spatial information techniques and spatial statistics: one case study of forest fire in Margalla Hills, Islamabad, Pakistan, 24.

Tariq A., Riaz I. \& Ahmad Z. (2020). Land surface temperature relation with normalized satellite indices for the estimation of spatiotemporal trends in temperature among various land use land cover classes of an arid Potohar region using Landsat data. Environmental Earth Sciences, 79(1), 1-15, DOI: 10.1007/s12665-019-8766-2.

Tariq A. \& Shu H. (2020). CA-Markov Chain Analysis of Seasonal Land Surface Temperature and Land Use Landcover Change Using Optical Multi-Temporal Satellite Data of. Remote Sensing, 12(20), 1-23, DOI: 10.3390/rs12203402.

UNEP (2005). 2004, Annual Evaluation Report UNEP. http://www.unep.org/eou

Vasenev V.I., Yaroslavtsev A.M., Vasenev I.I., Demina S.A. \& Dovltetyarova E.A. (2019). Land-use change in New Moscow: First outcomes after five years of urbanization. Geography, Environment, Sustainability, 12(4), 24-34, DOI: 10.24057/2071-9388-2019-89.

Vijayakumar S., Souza A.D. \& Schaal S. (2014). Bayesian backfitting for high dimensional regression School of Informatics, University of Edinburgh Institute of Perception, Action and Behaviour Bayesian Backfitting for High Dimensional Regression by. In School of Informatics, University of Edinburgh, 11.

Vishwakarma C.A., Thakur S., Rai P.K., Kamal V. \& Mukherjee S. (2016). Changing land trajectories: A case study from india using a remote sensing based approach. European Journal of Geography, 7(2), 61-71.

Yulianto F., Maulana T. \& Khomarudin M.R. (2019). Analysis of the dynamics of land use change and its prediction based on the integration of remotely sensed data and CA-Markov model, in the upstream Citarum Watershed, West Java, Indonesia. International Journal of Digital Earth, 12(10), 1151-1176, DOI: 10.1080/17538947.2018.1497098. 